\title{
Re-Examining Death: Doors to Resilience and Wellbeing in Tibetan Buddhist Practice
}

\author{
Tenzin Namdul 1,2
}

check for

updates

Citation: Namdul, Tenzin. 2021. Re-Examining Death: Doors to Resilience and Wellbeing in Tibetan Buddhist Practice. Religions 12: 522. https://doi.org/10.3390/rel12070522

Academic Editor: Deborah Orr

Received: 3 June 2021

Accepted: 5 July 2021

Published: 12 July 2021

Publisher's Note: MDPI stays neutral with regard to jurisdictional claims in published maps and institutional affiliations.

Copyright: (C) 2021 by the author. Licensee MDPI, Basel, Switzerland. This article is an open access article distributed under the terms and conditions of the Creative Commons Attribution (CC BY) license (https:// creativecommons.org/licenses/by/ $4.0 /)$.
1 Division of Epidemiology and Community Health, School of Public Health, University of Minnesota, Minneapolis, MN 55455, USA; namdu003@umn.edu

2 Earl E. Bakken Center for Spirituality \& Healing, University of Minnesota, Minneapolis, MN 55455, USA

\begin{abstract}
This paper explores how conceptions of death and the ways in which such conceptions shape responses to death determine ways of living as well as valued approaches to dying. The paper posits the question: can a fundamental understanding of death contribute to the development of adaptive social traits that lead to more sustainable phenomenological experiences of happiness and flourishing? Employing an anthropological lens, this work starts from the initial inquiry of "what is death?" by looking at cross-cultural historical and theoretical accounts of death and comparing the modern (medicalized) death to the Tibetan Buddhist notion of death. It examines how the practice of a "medicalized death" has shaped the understanding of contemporary death and the ways in which dying is approached. It employs the hermeneutic of a biopsychosociospiritual death to gain a holistic understanding of human mortality. This analysis, based on an 18-month ethnographic study among a Tibetan refugee community in southern India, explores the conception of death for this community using biological and cultural lenses. Moreover, it presents conceptions of death in Tibetan Buddhist culture, paying particular attention to how death is employed as an adaptive cultural tool in pursuance of positive behavioral changes and happiness at both individual and societal levels. In doing so, the paper presents both the theoretical conception of death and dying as well as its role in animating Buddhist cultural values and beliefs. Importantly, it presents a general landscape of Tibetan Buddhist cultural models that facilitate multiple ways of dying that are specifically dependent on an individual's familiarity with practices related to death and dying and his or her own level of engaging such spiritual practices.
\end{abstract}

Keywords: death and dying; resilience; Tibetan Buddhism; Tibetan medicine; biopsychosociospiritual; consciousness; brain

\section{Introduction}

The recent studies in the field of psychotherapy, specifically in the care of terminal patients, speak to the rather counterintuitive Tibetan Buddhist notions of death as a source of investigating self and forming positive behaviors, as well as a means to generate resilience and compassion. Michael Pollan's book, "How to Change Your Mind: What a New Science of Psychedelics Teaches Us about Consciousness, Dying, Addiction, Depression, and Transcendence" (Pollan 2018) also testifies to this. Having earned a reputation for exploring the complex interplay of nature and culture, Pollan explored the relationship between hallucinogenic plants (psilocybin) and the Western cultural fear of death. Pollan narrated some impressive results of clinical trials at NYU and Johns Hopkins School of Medicine where researchers administered psilocybin to cancer patients in an effort to relieve their anxiety and existential distress.

Pollan further explained that according to the researchers he interviewed, patients reported transcendental feelings of profound love, calmness, and a loss of fear of death after a session of psilocybin. Likewise, patients experienced a dissolution of self along with a sense of connectedness to others. This was validated via fMRI, which showed that the activity in the part of the brain called the "default-mode network" that relates to the construc- 
tion of an "autobiographical self or ego" was noticeably reduced (pp. 351-52). Moreover, a double-blind clinical study showed that an administration of a single dose of psilocybin produced substantial and sustainable decreases in depressed mood and death anxiety in patients with life-threatening cancer (Griffiths et al. 2016; also see Grob et al. 2013).

These reports were consistent with what I had repeatedly heard from my interlocutors during my dissertation fieldwork in Tibetan communities in southern India. It is worth mentioning that the use of psychedelic mushroom (Amanita muscaria) in a Buddhist alchemical tradition in the 2nd and 9th centuries (Hajicek-Dobberstein 1995) or in a typical Vajrayana initiation (Crowley and Ann 2019) have been recorded. The use of psychedelics in the practice of Buddhism is associated with gaining an access to one's unconscious mind and either painful experience or supreme realization of "universal love" (Stolaroff 1999, p. 61), as well as acquiring an avenue where one's "self and reality can be experienced and organized" (Tart 1991, p. 139). However, I have not witnessed or heard of the use of any psychedelics in Tibetan Buddhist monastic or lay practitioners. Rather, the use of epistemology that informs the mind and its function, particularly during death, is viewed as a potent ground in experiencing self and reality.

For Tibetans, death is more than an event or an end point. ${ }^{1}$ Death, according to the Tibetan Buddhist monastics I interviewed in Mundgod, is rather viewed as a phenomenon that informs key Buddhist concepts, as well as being a biological process that can be employed to engage in potent meditative practice aimed at achieving a state of selflessness and profound love for others. As one of my monk informants, who was caring for a senior monk with terminal illness, explained: "such a state of mind helps to generate resilience toward pain and suffering".

Geshe ${ }^{2}$ Samten, one of the monks with whom I spent considerable time in the field, said, "thinking about death helps me to internalize the concept of impermanence". Geshe Samten would go on to describe how the transience of our existence that frames the reality of death for all of us motivates an understanding of the impermanence of all things in life. Thus, this view of death is central to the Buddhist concept of the impermanence of all conditioned phenomena. Likewise, an elderly lay Tibetan acknowledged that being aware of death motivates him to reduce greed and attachment. Furthermore, akin to what psilocybin clinical trials have demonstrated, some Tibetans, particularly Buddhist practitioners, relate a sense of joy, fulfillment, and love at the moment of impending death, as well as during post-clinical death meditation, where they are in the state of pure luminous mind. Tibetan Buddhist practitioners refer to this post-death meditation as thugs dam $^{3}$ (pronounced tukdam), which I will elaborate on further in another article. These myriad ways in which Tibetans conceive of death and apply it in their life provide a fertile ground from which to examine the relationship between life and death.

In this paper, I draw from my 18-month ethnographic study in Tibetan refugee communities in southern India in an attempt to explore how the manner in which we conceive of death and the ways in which we respond to death determine the ways we live and die. Can a primal account of death contribute to the development of adaptive social traits that could lead to sustainable happiness and human flourishing? Employing an anthropological lens, I address the initial inquiry of "what is death?" by looking at the historical and theoretical exploration of death and compare the modern (medicalized) death to the Tibetan Buddhist notion of death. I explore the concept of "biopsychosociospiritual" death to gain a holistic understanding of human mortality. This analysis, based on ethnographic data and existing literature, as well as a reflexive approach rooted in my dual role as an anthropologist and a Tibetan medical doctor, explores the conception of death using biological and cultural lenses. It further examines how the practice of "medicalized death" has shaped the understanding of contemporary death and the ways in which we are dying.

Moreover, I present conceptions of death in Tibetan Buddhist culture, paying particular attention to how death is employed as an adaptive cultural tool in pursuance of positive behavioral changes and happiness at both the individual and societal levels. In doing so, I present both the theoretical conception of death and dying as well as its role 
in animating Buddhist cultural values and beliefs. Importantly, I present a general landscape of Tibetan Buddhist cultural models that facilitates multiple ways of dying that is specifically dependent upon an individual's familiarity with death and dying and his or her own level of spiritual practice. Finally, I hope the aforementioned discussion will shed light on a fundamental question: What does death mean for someone who believes in reincarnation?

\section{What Is Death? New Answers to an Old Question}

Clearly, death is not a self-evident phenomenon. The margins between life and death are socially and culturally constructed, mobile, multiple, and open to dispute and reformulation. (Lock 2002, p. 11)

Pema ${ }^{4}$ had been unconscious for six days when I went to see her, accompanied by her uncle, in the Intensive Care Unit (ICU). She was lying motionless, hooked up to multiple tubes, breathing via tracheostomy, a medical procedure where an opening is made in the throat to insert a tube into the windpipe in order to deliver air directly to the lungs. A nurse, who was observing an electrocardiogram (ECG) and other vital signs displayed on the nearby monitor, smiled at us. She scribbled something on the patient record board tied to the foot of the bed and left the station without saying anything. Pema's parents were standing by each side of the bed as if waiting for their daughter to respond and start talking to them. Despite looking tired and a little shaken, they greeted me warmly and thanked me for coming.

Six days earlier, Pema had been found unresponsive by her uncle early in the morning in her room. The family, not knowing what might have caused the condition, rushed her to the nearest hospital with an ICU facility, in a nearby Indian city, which was an hour-and-a-half drive away. They realized later that Pema had ingested a high dose of a chemical causing neurotoxicity, which led to severe brain damage. Pema's uncle called to ask my opinion four days after the incident. When I asked for more information about Pema's condition, he told me that the head neurologist at the hospital had said there was nothing much they could do, and that Pema was "brain dead". The family was given an option to unhook the life support. However, they also had another Tibetan medical doctor who had come to see Pema before me. The Tibetan doctor, after careful examination of Pema's condition, had told them to wait for at least two weeks before giving up on her.

Pema's family might not have been aware that Pema would have made a good candidate for organ donation if they had agreed to declare her brain dead. In such cases, if the doctor saw that she could not breathe on her own after being disconnected from her ventilator, she would be legally "brain dead". Pema would be then hooked up back to her ventilator to keep her organs fresh for transplant (Teresi 2012). I was curious to understand what made the two doctors decide on how to advise Pema's family.

The head neurologist was surprisingly open about talking to me when I reached him over the phone. He said he was swamped with meetings when I called him but agreed to a conference call the next day.

"I hope you know the patient's condition is irreversible", he said as we began our conversation the following day. I asked him what he meant by Pema's condition being irreversible.

"You mean she is untreatable or there is no point in treating her?"

"We could continue to treat and observe her but even if she regains consciousness, she would never be the same as before".

I started to wonder about the extent of Pema's brain damage. "How do you explain that?"

"See, the patient's cerebral cortex (responsible for higher thought processes including decision-making, speech, social interaction, and so on) is significantly damaged. She is not aware of herself and her surroundings. The impact is such that it could be very hard to reverse the situation. She could never be a complete person".

"I spoke to Pema's family, and they are wondering if you could continue with your observation of her and see how she does in the next few days?" 
"We could certainly do that", he responded. We decided to stay in touch before we hung up the phone.

Later that day, I went to the Men-Tsee-Khang ${ }^{5}$ clinic to meet with the Tibetan medical doctor to ask him about his analysis of Pema's condition. When asked why he advised Pema's family to continue to keep her under observation, the Tibetan doctor told me that even though Pema was unresponsive, her pulse ${ }^{6}$ was firm and strong, and, as if to emphasize Pema's mental agility, he added: "She was full of emotion. She got all teared up when I was talking to her parents. Her consciousness was intact". Pema's parents later corroborated the Tibetan doctor's assertion that her eyes had welled up with tears when they were speaking to the Tibetan doctor.

It was interesting to see that while Pema was lying in the ICU unable to intervene in what was being thought of her and planned for her, the doctors were directing life-anddeath decisions for her-and with distinctly different lenses on her state of consciousness. Whilst the Indian neurologist had the "brain" as a key marker in determining Pema's mortality, arguing that Pema could never be the person that she used to be, the Tibetan doctor, on the other hand, had her "consciousness" as a primary reference in contesting his view that she was very much conscious and alive.

The neurologist answered my call with enthusiasm when I called him exactly two weeks after Pema was admitted to the ICU. He told me that Pema had regained partial awareness and part of her damaged brain had started to heal, showing good signs of recovery. He also said that all her vital signs, including blood pressure, respiration, pulse, and body temperature, were stable and normal. Most importantly, he said, they had not noticed any seizures. The neurologist thought Pema's recovery was nothing less than a miracle and that he had high hopes for Pema's recovery. Pema did recover swiftly in the following days: she was taken off the ventilator, was aware of her surroundings. Within a week, the neurologist felt she was ready to go home. Pema was discharged in a stable condition a little more than three weeks after she had been admitted with a little hope of recovery. Other than some difficulty in walking and maintaining balance, Pema has, since then, fully recovered.

Pema's case is fascinating not only because of the way it animates the existing conundrum relating to death but also because it adds another layer for us to consider. The Tibetan doctor, besides being cognizant of Pema's unresponsive state, was using consciousness as a point of reference that is distinctive from the way death is conceived in neurocentric death (Laureys 2005). Understanding this consciousness-centric approach is critical to this research because of a recurring pattern throughout the course of my fieldwork where caregivers-Tibetan medical doctors (TMDs), Tibetan Buddhist monks (TBMs), and family members (FMs) - held the collective goal of caring for a dying person's consciousness. Similarly, I witnessed that consciousness plays a key role in drawing the line between life and death. For the caregivers, a person is alive as long as consciousness has not left the body. It was interesting to observe with all the aforementioned stakeholders (TBDs, TBMs, and FMs) that when a person's physical body starts to break down, the consciousness is the entity that is perceived to need the utmost care, albeit the stakeholders employ different methods to do so. Nonetheless, before I present the way death is conceived and employed in Tibetan Buddhist community life, I think it is important to get a sense of how the conception of death has evolved in modern biomedicine and why considerations about death have ended up being so contentious.

\section{Cardiorespiratory to Neurocentric Death}

The way we understand and treat death speaks volumes about our relationship to death. The attempt to understand death (mortality) is virtually contingent on the origins of human self-consciousness; it is the central issue of Homer's epic poetry (circa. $800 \mathrm{BCE}$ ). Despite a plethora of recent scholarship on death and dying (Beecher 1968, 1970; Becker 1973; Kaufman 2005; Laureys 2005; Belkin 2014; Braswell 2014; Norwood 2009; Bishop 2011; Gawande 2014, to name a few), death remains poorly understood with a lack of consensus across disciplines (Magnus 2015). Interestingly, the medical/academic debate surrounding 
a clearer definition of death has not changed since it started more than half a century ago. French neurologists, Mollaret and Goulon (1959) question if we even have a right to terminate treatment employing criteria that pretend to understand the boundary between life and death. Likewise, Henry K. Beecher, a pioneering medical ethicist and chairperson of an Ad Hoc Committee of the Harvard Medical School convened to examine the issue of irreversible coma, said, "Only a very bold man, I think, would attempt to define death" (Beecher 1970, p. 471).

The perplexing nature of defining death can be traced to modern technology, for the concept of death has continued to evolve with progress in technology, particularly with the invention of the positive pressure mechanical ventilator and electroencephalogram (EEG) in the 1950s (Beecher 1968, 1970; Laureys 2005). There is a certain irony in a dying/dead person's life being sustained by artificial respiratory support with an EEG while simultaneously pronouncing that person dead.

Biomedicine's attempt to determine death has never been more contested than today, despite a continuous endeavor to master the definition of death under the guise of technology and law. Dick Teresi (2012), a notable science journalist, argued that, rather than illuminating death, modern technology has "only expanded the breadth of our ignorance" (p. 4). Haider Warraich, a cardiologist at Duke University Medical Center, in his effort to articulate how modern biomedicine has created a modern death and changed the end of life, writes:

Not only have biomedical advances changed the ecology, epidemiology, and economics of death, but the very ethos of death-in the most abstract possible sense- - has changed. Far from being clearer, the line between life and death has become far more blurry. (Warraich 2017, p. 9)

The aforementioned climate in the care of the dying has given birth to divisions between the cardiovascular system, the respiratory system, and brain, where a dying person, like Pema, could be viewed as dead or almost dead while the rest of her body is circulating and functioning normally. In this context, it is crucial to be aware that the conception of "consciousness" is fundamentally different in the Tibetan Buddhist cultural model compared to biomedicine because consciousness is not conceived as being tantamount to the organ of the brain (Varela 1997). This division has thus paved the way for both conceptual and practical shifts where neurocentric-death superseded the traditional approach of employing cardiorespiratory cessation as a primary marker in determining death. However, it is noteworthy that the division between cardiorespiratory and brain death, viewed against the background of a broader debate of biological and socio-cultural understanding of death, clarifies the historical and theoretical perspectives, as well as underlying forces, that led to the current contentious understandings of death.

\subsection{Historical and Theoretical Background}

Despite the modern Western cultural reticence about engaging in conversation related to death or the ostracizing of dying people, philosophers and anthropologists have embraced the study of death with open arms (Becker 1973; Bloch and Parry 1982; Robben 2004; Halifax 2008; Jacobsen 2013; Thompson 2015). Anthropological studies, in particular, have shown that the way humans understand death and deal with dying reflects particular cultural worldviews and practices (Metcalf and Huntington 1979). Nevertheless, anthropologists have critiqued the 'exoticization' and 'parochialization' of death and called on the discipline to engage in cross-cultural analysis, which is the strength of anthropological investigation (Palgi and Abramovitch 1984).

Throughout human history, death has been known by two obvious characteristics: as primitive and as universal. Death remains unfamiliar territory and is viewed with utmost dread and fear, and it engenders incredible differences in responses across cultures. Metcalf and Huntington (1979) articulated similar remarks about the human response to death in the introductory chapter in their monograph dedicated to a cross-cultural examination of death rituals. Since then, over the past five decades, scholars from var- 
ied disciplines, specifically anthropologists and bioethicists, have expanded the inquiry into the "mystery" of death and dying. This inquiry, as observed by numerous scholars (e.g., Kaufman and Morgan 2005; Lock 2002; Brussel and Carpentier 2014; Braswell 2014; Bishop 2011; Lamb 1985; Beecher 1970), has added an additional layer of complexity—that of the dichotomization of biological and socio-cultural approaches to death.

\subsection{Biological and Socio-Cultural Death}

Death has been universally considered as an event of social significance, and every known culture has devised rules and norms for defining death as the final rite of passage, and for dealing with its consequences (Riley 1983). However, changes in social organization and cultural practices during the last two centuries have generated an ongoing dispute regarding the conception of death in the sphere of academia as well as amongst the general public (Lock 2002; Kaufman and Morgan 2005). This debate reflects a fundamental dichotomy: the difference between biological and social death-also known as death of the organism and death of the person (Braswell 2014). This contestation has challenged the authority of biomedicine in medicalizing death as well as in deconstructing the way death is defined.

In the early twentieth century, scholars such as Robert Hertz and Arnold van Gennep studied societies that do not view death as an "event or instantaneous" (Metcalf and Huntington 1979). Likewise, social thinkers and cultural analysts have contended that death is never independent of its cultural milieu; rather, it is strongly attached to specific social, cultural, and historical circumstances (Jacobsen 2013; Gross 2003; Lock 2002). The cultural practices associated with death reveal fundamental social and cultural beliefs. Hertz, for example, in his seminal work on funeral rituals of the Dayak of Borneo in Indonesia, pointed out the way people would recognize a period when the dead person is neither alive nor dead. Hertz referred to this period as an "intermediary period" and said that the end of this state is celebrated by a "great feast" (Hertz 1960, p. 54). Nevertheless, the concept of social death has gradually been overshadowed by the re-definition of death — based on the brain—advocated by medicine and law (Baron et al. 2006; Lock 2002).

The Neurological Determination of Death (NDD) primarily came into the discussion when Mollaret and Goulen published their influential work in 1959, coining the term "coma depasse" which means "a state beyond coma" (Mollaret and Goulon 1959). Initially intended to define the futility of care in such cases, the introduction of organ transplantation inexorably led to linking the issues of "brain death, with organ procurement, and transplantation which has continued into current medical practice" (Baron et al. 2006, p. 603).

In August 1968, the Ad Hoc Committee of the Harvard Medical School published a report, proposing an irreversible coma as the "new criterion for death" (p. 85). The report justified this new criterion by asserting that only the introduction of mechanical ventilation was able to sustain respiration and heartbeat in irreversibly comatose persons, even after the cessation of whole brain function (Braswell 2014). The Ad Hoc report, however, led to confusion, as even though brain function could not be resumed by any medical means, there was no procedure to withdraw treatment. The Committee-in response to this confusion-proposed to categorize such patients as "brain dead". This proposal would not only make it possible to remove "medically ineffective life-sustaining treatment, but also make them an organ donor candidate" (1968, p. 87).

Nevertheless, the Ad Hoc Report was constantly scrutinized. The conference of Medical Royal Colleges and their Faculties in the UK published a statement focused on Mohandas and Chou's emphasis on the importance of irreversible loss of brainstem function. This later led to the formal adaptation of the brainstem formulation of "brain death" in 1995 (Baron et al. 2006). Despite these numerous guidelines, the conflict between whole-brain death and brainstem death has not been resolved.

A point of departure for a formulation of socio-cultural death is the pivotal work of French sociologist Robert Hertz (Braswell 2014). First published in 1906, Hertz asserts in his essay "The Collective Representation of Death" that death dismantles both the individual's "visible body life" and "social being" (Hertz 1960, p. 77). This dismantling causes the deceased person's community to enter a "mortuary state" similar to the deceased's own. 
By engaging in mourning, the community members detach the deceased person's social substance from his or her physical form (Braswell 2014). In so doing, the individual is able to transit into the afterlife, while the community members are able to come back to the "world of the living" (Hertz 1960, p. 75). Death is therefore not an isolated biological event, but rather a social process that concludes with the rebirth of the deceased person as well as the community. Hence, the death of the person must be comprehended as a "fluid concept" that is structured in "social practices of recognition" (Braswell 2014, p. 59).

Hertz further argues that the terror inspired by the corpse does not arise from the mere observation of the physical changes that happen to the body. For Hertz, such a simplistic explanation of death is not adequate because a death in a particular society can arouse extremely different emotions and variable intensities based on the social status of the deceased. For example, the death of a person of high social ranking or chief status could raise true panic among the community, whereas the death of a stranger, a slave, or a child might hardly be noticed, with no emotion or ritual (Hertz 1960, p. 76). Moreover, the social aspects of death are reflected in how the dead body is treated. For instance, children, who are not yet considered full social beings, are denied a secondary burial. Thus, for the death of children, there is no reason to go through the extended pain of returning them to the spirit world to which they are still partly attached (Hertz 1960, p. 84). The death of the person, then, cannot be simply reduced to physiological phenomena, and "to the organic event is added a complex mass of beliefs, emotions and activities which give it a distinct character" (ibid., p. 27).

Contrary to Hertz, there is an assumption in contemporary Western culture that death and dying are, of course, biological phenomena, associated with the "cessation of heartbeat and breathing followed by ongoing process of disintegration" (Brussel and Carpentier 2014, p. 2). However, as discussed earlier, the conception of biological death is both contested and evolving. It is important to note that these attempts to specify criteria of death are shaped by legal concerns more than anthropological interest.

David Lamb, in his influential book, Death, Brain Death, and Ethics (1985), emphasizes that in order to systematically analyze an account of death in biomedicine, it is necessary to differentiate between "systematic death" (or death as traditionally understood) and "brain death" (p. 4). Systematic death, here, refers to irreversible cessation of cardiorespiratory function, whereas brain death refers to the total irreversible dysfunction of neuronal components that encompass cerebral hemispheres, brainstem, and cerebellum (Lamb 1985; Korein 1978). According to Lamb, cardiorespiratory arrest is only a mechanism for causing brain death.

\subsection{Brain Death}

Brain death, however, acquired worldwide recognition only after being proposed by the 1968 Report of the Ad Hoc Committee of the Harvard Medical School. The Ad Hoc Report laid out four conditions as criteria of brain death: (1) absence of cerebral responsiveness; (2) absence of induced or spontaneous movement; (3) absence of spontaneous respiration-requiring the use of the respirator; and (4) absence of the brainstem and deep tendon reflexes (Lamb 1985, p. 53). The realization of the importance of "brainstem death" following the Ad Hoc Report was felt gradually. Referring to the brainstem as the essential component or "physiological kernel" of the brain, Lamb expounds on the relationship between brainstem and brain death:

The brainstem contains (in its upper part) crucial centers responsible for generating the capacity for consciousness. In its lower part, it contains the respiratory center. It is death of the brainstem (nearly always the result of increased intracranial pressure) that produces the crucial signs (apneic coma), which doctors detect at the bedside, when they diagnose brain death. (Lamb 1985, p. 5)

In the context of brain death, the death of the brainstem, therefore, became synonymous with the death of the individual. Lamb, however, makes a distinction between brainstem death and a persistent vegetative state (PVS). He contends that a substantial brain impairment condition is largely restricted to the cerebral hemisphere, sparing most of the brainstem, especially the capacity to breathe. Nevertheless, the conflict between whole 
brain death and brainstem death still continues. The Uniform Declaration of Death Act (UDDA), for instance, was drafted in 1981 by the President's Commission for a study on brain death and was shortly approved by the American Medical Association as well as the American Bar Association. The Act stated that "an individual who has sustained irreversible cessation of all functions of the entire brain including the brainstem, is dead" (Baron et al. 2006, p. 605).

Steven Laureys, an acclaimed researcher in the field of neurology of consciousness and the head of the Coma Science Group, affirmed that the most accepted definition of death is the "permanent cessation of the critical functions of the organism as a whole". For Laureys, "critical functions are those without which the organism as a whole cannot function-control of respiration and circulation, neuroendocrine and homeostatic regulation, and consciousness" (Laureys 2005, p. 900). It is interesting to note that Laureys identifies 'consciousness' as one of the criteria in determining death. However, it is pertinent to understand that the consciousness Laureys is referring to is applied in the context of the nervous system, where the brain's higher functions in the neocortex are interpreted as consciousness. Nonetheless, Laureys also recognizes the problematic nature of assessing the state of consciousness in pronouncing brain death by stating "clinical testing for absence of consciousness is much more problematic than testing for absence of wakefulness, brainstem reflexes and apnoea in whole brain or brainstem death" (p. 905).

When I asked the Tibetan doctor what he meant by Pema being conscious, he told me Pema, as a person, was consciously aware of the situation, her condition, and had a desire to get better. The Tibetan doctor gave the impression that Pema's emotional response to her parents' suffering, and her desire to get better, could motivate her to pull herself out of her dire condition. Francisco Varela, a renowned neuroscientist and a strong proponent of an interdisciplinary approach to the study of consciousness, in his dialogue with the Dalai Lama on the importance of examining the relationship between self and consciousness in Buddhism, said:

First of all, the analysis has to do with the self as agent and the self as experiencer. In this sense it's very important. But now let us look to the flow of our experience: feelings of sadness and so forth arise in response to certain experiences. Then certain desires arise in our consciousness. From such desires the motivation to act may arise, and together with this motivation to act comes a sense of self, of 'I'. (Varela 1997, p. 113)

Informed by the complex understanding of mind in Tibetan Buddhist culture, the Tibetan doctor was perhaps looking at Pema's consciousness beyond her neural capacity, and such an approach could cause disagreement in diagnosing a patient when brain and consciousness are viewed as connected but not the same. Moreover, the Tibetan Buddhist interpretation of subtle and extremely subtle consciousness, which I have elaborated further elsewhere, transcends the more agreed upon notion of biological death. ${ }^{7}$

\subsection{The Problem with Viewing Death as a Biological Event}

Given that a disintegration of a person impacts the person's physical body, psychological mind, and sociocultural milieu, one cannot dismiss any of these components while caring for a dying patient. This is what Jeffrey Bishop, a physician and moral philosopher, argues with regard to caring for the dying. Focused on contemporary medical practice, Bishop proposes a "biopsychosociospiritual" model, asserting it as "comprehensive" care: "It is holistic, covering the whole of human thriving. It is about total care, and in this sense, it is totalizing" (Bishop 2011, p. 251). In such a scenario, an understanding of death solely as an isolated biological event denies death as being a dynamic social process and negates the holistic understanding of death (Braswell 2014). Bioethicists Braswell (2014) and Bishop (2011) have observed that the omission of a dynamic social understanding of death has shown to be highly damaging to patients from the bioethical standpoint. Furthermore, recent anthropological scholarship has illustrated how focusing solely on the biological interpretation of death not only creates confusion but also makes little sense in 
other cultural settings. For example, ethnographic studies such as Margaret Lock's work in examining brain death cross-culturally in the US and Japan and Tanya Zivkovic's study of a Tibetan Buddhist understanding of death in northeast India showcase the complexity of the debate surrounding biological and sociocultural conceptions of death.

Margaret Lock explores the manner in which advances in medical instruments have enforced a reassessment of the recognized boundaries between life and death and how these debates mirror strong "social values and political interests" (Lock 2002, p. 2). She investigates why a highly technologically developed nation like Japan expresses strong resistance to brain death as equivalent to human death in contrast to North America or most of Europe. Even though many of Lock's informants relate their reservations to brain death to being "subjected to abuses of medical power" rather than to their culture (ibid., p. 6), she noted that death in Japan signifies more than the destruction of individual bodies: "It is above all a familial and social occasion" (ibid., p. 8). For the Japanese, she asserted, it is unacceptable to ascribe death to a specific moment. Dying is generally perceived as a process, and thus cannot be "isolated as a moment" (ibid., p. 8).

Relating to "brain death", Lock makes a contentious claim that organ procurement, a euphemism for organ harvesting, is largely responsible for the redefinition of death, giving birth to a "new" brain death. She asserts that if it were not for technological development used in organ transplants, that the "brain-dead" definition of death might not exist. She writes: "A 'living cadaver', as the brain-dead were first called, is created by an accident and sustained by medical technology" (p. 1). In essence, she argues that organ transplants are institutionalized and commoditized by the collaborative work of modern medical technology and its associated legal framework. The definition of death focused entirely on the activity of the brain is a product of the need to provide for a legally regulated procedure that facilitates organ transplant. It is a theory created in the service of a practice; as such, it omits inconvenient aspects of the phenomenon, with significant bio-ethical consequences. She argues that when the death of individual bodies is made into a measurable biological event, employing specific parts of the body (specifically in ICUs), the social importance of death is naturally minimized.

The importance of social death is emphasized by a host of researchers, demonstrating how culturally relevant practices such as death rites, mourning, certain beliefs, etc., play an important role in dealing with the inevitable nature of death (Becker 1973; Hertz 1960; Metcalf and Huntington 1979). Moreover, social death negates the uncertain nature of physical death by obscuring the divergence between the inevitable process of biological death and the social recognition of the end of life, in a process that is carefully orchestrated (Lock 2002). Arguing that death can never be "divorced from culture", Lock writes: "Death is not a self-evident phenomenon. The margins between life and death are socially and culturally constructed, mobile, multiple, and open to dispute and reformulation" (Lock 2002, pp. 11-12).

Another important difference is the institutionalization and legitimization of brain death as end of life in the West as there is no objection from legal and religious institutions. It certainly is instrumental in the routine procurement of organs across North America and much of Europe. This is not the case in Japan. Even though the Japanese are technologically highly developed and are adept at dealing with the technological difficulties of organ transplant, there is a strong influence of Buddhist philosophy ${ }^{8}$. For example, in the Buddhist tradition, it is believed that even after complete cessation of brain and cardiac function, the person remains in the process of dying, and in some cases, deceased persons are able to transmogrify through reincarnation (Zivkovic 2014; Thompson 2015).

Tanya Zivkovic's ethnographic study relates the social life (or a social death) of a deceased Tibetan Buddhist lama and his relationship with his faithful devotees in Darjeeling, India. Zivkovic follows the life course of a spiritually acclaimed Tibetan lama, Kenchen Sangay Tenzin, and his young, reincarnated successor, Tenzin Kunga Gyaltsen Rinpoche. Highlighting the potential contradiction between biological and cultural interpretations of life and death from her study of these lamas, Zivkovic calls for greater critical attention to culturally specific 
understandings of life and death because the acceptance that our life courses are 'natural' and "that biology determines our experience of death has little relevance to the life histories of eminent Tibetan Buddhist lamas" (Zivkovic 2014, pp. 172-73). Zivkovic argues that the life histories for these lamas do not cease with biological death; rather, the social life of Buddhist lamas continues through the media of supranormal activities, such as relics, reincarnation, bodily transmogrification, and hagiography. Tibetan lamas-for whom death is not an end but a continuum of life-are therefore not confined to the biological interpretation of death that rests on the brain death or physical dissolution of a person.

\section{Tibetan Buddhist Notion of Death}

I noticed during my fieldwork that although the subtlety with which death was articulated varies among Tibetans, one of the most common conceptions of death was: "Death is a natural phenomenon of the world; everything born will eventually die" (Tib. 'chi ye ni 'jig rten gyi chos nyid red skyes ba thams cad 'chi rgyu red). The dictum on death might sound rather banal, but linguistically and symbolically, it carries a strong and persuasive meaning. To illustrate, the two middle syllables "“jig rten", though generally understood as "world", are a composite phrase that literally means "disintegrate and basis". Hence, the tenet of Tibetan Buddhist cosmology that everything that arises, or is part of the base of existence, will eventually disappear/collapse, informs the way that life and death are conceived. Likewise, to expound on what Geshe Samten related earlier, the fact that everything that integrates-including life and everything in naturehas to disintegrate helps to illuminate the Buddhist concept of impermanence: nothing is permanent, and everything is in a constant state of flux. This cultural worldview offers a firm foundation to build an explanatory model for understanding death using multiple perspectives. Furthermore, the mechanism of this foundational ground of viewing death as an intrinsically natural phenomenon of the world draws upon Buddhist psychophilosophical and medical conceptualizations.

In the rgyud bzhi (the Four Tantras), the canonical root text of Tibetan medicine, a direct connection is drawn between birth and death in the spectrum of experience in human life. The medical text states that a mother cannot conceive and that nothing can come into life without the support of consciousness (Gonpo 2015, p. 46). At the other end of the spectrum, no one is considered dead until the consciousness leaves the body (also see Varela 1997). Reflecting on how the Tibetan doctor examined Pema in the ICU, I observed throughout my fieldwork that the aforementioned cultural model of assigning the most importance to consciousness to determine life or death is the greatest factor that informs caregivers while caring for the dying. The Dalai Lama, in his interaction with Western scientists and philosophers, stresses that death in the Buddhist view is not a death of a specific organ as in modern biomedicine; rather, it is the death of the entire person. He said, "According to Buddhism, the definition of death has to be understood in contrast to the definition of life. Life is defined as the basis for consciousness. As soon as the body is no longer able to support consciousness, there is death" (Varela 1997, p. 141).

\section{Bardo: Death as a "Moment of Transition"}

One of my interlocutors told me, rather casually yet profoundly, that "Death is analogous to going where you came from. It's like going back home". For Tibetan Buddhists, death is viewed more as a state of transition, which they refer to as a bardo, literally meaning a gap between two things or an interval. They thus view death not as a dead-end, but rather as a transitional moment between two of the six intervals or bardos that form the cycle of existence (Thompson 2015, p. 285).

These six bardos begin with the (1) "bardo of this life" (skye gnas bardo), which spans from the moment of birth to the start of active dying. Within the bardo of this life is another bardo-(2) the "bardo of dream" (rmi lam bardo), which starts at the beginning of sleep, comprising dreaming and deep sleep and concluding with waking up; and (3) the "bardo of meditation" (bsam gtan bardo), which is the moment when the mind takes a time-out in meditative immersion. (4) The "bardo of dying" ('chi khai bardo) begins where the 
"bardo of this life" ends, starting with active dying and concluding at the moment of death. Subsequently, there is (5) the "luminous bardo or dharmata" (chos nyid bardo) that occurs during the after-death experience of the "clear-light" or "ground luminosity", which is considered the ultimate nature of mind as pure awareness, concomitant to a time deemed clinical death in biomedicine. This is also the moment the Tibetan Buddhist practitioners recognize as the moment of profound peace and pristine awareness, a perfect time to enter into the state of thugs dam. However, they issue a caveat that one who has not practiced during this life of lived experience will not recognize this stainless moment of awareness and can instead enter into a state of delusion. Finally, (6) the "bardo of becoming" (srid pa bardo) is the time after the "luminous bardo or dharmata" when the subtle consciousness wanders in search of a new physical embodied form until it enters the womb of its future mother in that form and starts the whole cycle again (Thompson 2015, p. 285).

With such expansive guidelines about death and dying, Tibetans seem to have inherited a cultural buffer of not having to conform to the binary states of being either dead or alive-the concept of the bardo provides an option to conceptually choose an in-between state, even without an in-depth knowledge of the "pristine awareness" moment (see Germano 1997 for the use of death and dying in finding spiritual opportunity).

Against the background of contemporary Western culture where death is feared, avoided, and often viewed as mysterious, and death is a state from which no one can come back to report, the centuries-old Tibetan Buddhist view of death as situated in their worldview is riveting and affirming. However, it was not always the case in the West that discussion of death provoked a gaze as if staring directly into the blazing sun. Seneca (2018), a Roman Stoic philosopher famously said, "he lives badly who does not know how to die well", and posed an important question to the Roman public, "What's to be feared in returning to where you came from?" Similarly, Aries (1974), a French medievalist and historian, in his seminal work on attitudes toward death in the West in the medieval era, argues that people of the time not only viewed death as normal but were acutely aware of their own death, accepted it, and were prepared for it.

Having said that, as I mentioned earlier, the fascinating aspect of a Tibetan Buddhist cultural death model is the way in which death and dying are understood from a multiperspective approach — philosophical, biological, psychological, social, and spiritual—and employed as a moral compass in transforming one's behavior as well as one's view of oneself, others, and the world (as illustrated in Figure 1). This model is similar to what Bishop urged to be adopted in biomedical practice, where "total care" could be provided to a patient via a "biopsychosociospiritual" model (Bishop 2011, p. 251). For Tibetans, their model of death is not only about caring for the dying but also serves as a psychological adaptation tool in crafting their view of their next life via living well and preparing to die well in this life.

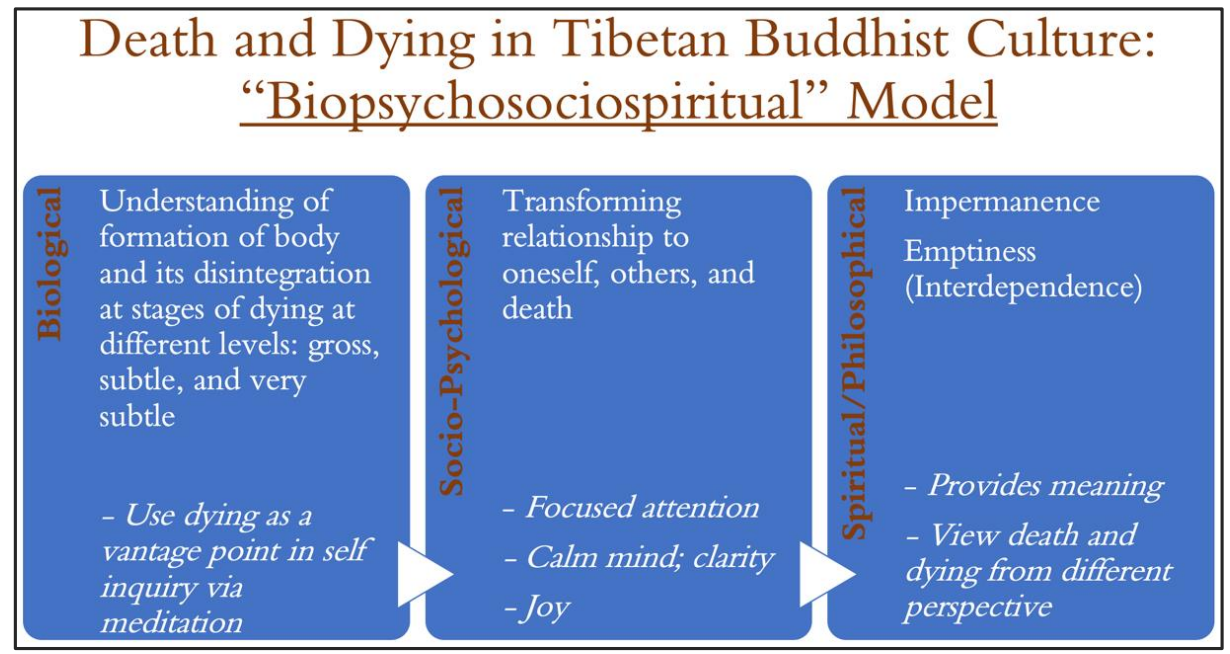

Figure 1. Tibetan Buddhist death model: the "biopsychosociospiritual" model. 


\section{How Do We Respond to Death?}

Death will always remain a mystery; nevertheless, the cross-cultural investigation of death will continue to provide insights into how humans cope with that mystery. (Abramovitch 2001. Anthropology of Death).

Western contemporary culture has chosen to look the other way or treat death as the "elephant in the room", but if we pause to look at death, it is quite an interesting human phenomenon. We have complete certainty that everyone will die, but a caveat to this is the complete uncertainty as to where and when one might die, or about what (if anything) comes next. Of course, this has caused a sense of fear and helplessness among us, and in our response to this, we have come up with myriad ways to either make peace with death, confront death, or at times, endeavor to conquer death (Kubler-Ross 1969; Metcalf and Huntington 1979; Green 2008; Bishop 2011).

The cultural anthropologist Ernest Becker, in his acclaimed book, The Denial of Death (1973), makes a provocative argument that humans are driven "crazy" by the idea of being mortal. Becker asserts that humans are terrified of death and thus have resorted to denying and keeping death unconscious. Becker, in fact, attributes this torment around the concept of death as the cause for developing everything that is culture in human societies. He writes:

Everything that man does in a symbolic world is an attempt to deny and overcome his grotesque fate. He literally drives himself into a blind obliviousness with social games, psychological tricks, personal preoccupations so far removed from the reality of his situation that they are forms of madness-agreed madness, shared madness, disguised and dignified madness, but madness all the same. (Becker 1973, p. 27)

\subsection{Terror Management Theory: Mortality Salience}

Becker's hypothesis, though, initially ridiculed by academics, gained ground as an important anthropological theory known as "Terror Management Theory" with an impressive work and series of publications related to "mortality salience" by Jeff Greenberg, Thomas Pyszczynski, and Sheldon Solomon, particularly in the mid-nineties (Teresi 2012; Greenberg et al. 1997). Dick Teresi, in his conversation with Solomon while doing research for his book, The Undead (2012), reported that Solomon and his colleagues started their study questionnaire with these directions: "Please describe the emotions the thought of your own death arouses in you. Jot down, as specifically as you can, what you think will happen to you physically as you die and once you are physically dead" (Teresi 2012, p. 8). Solomon and colleagues found intriguing results where groups who were exposed to "mortality salience" engaged in behavior such as berating people who did not share their worldviews, trying to convert them into their system of beliefs, or even killing them. For instance, their study reported that judges subjected to the experiment were much harsher with their judgment: "The judges who had been reminded of their mortality set bails that were nine times as high [as the control group]" (Teresi 2012, p. 9).

In one of their influential studies, Solomon and colleagues posited that humans possess a "dual-component cultural anxiety buffer: worldview and self-esteem" (Solomon et al. 1991, p. 93). These two buffers, according to Solomon and colleagues, help an individual to lessen the anxiety about death by maintaining meaning provided by a cultural worldview and acquiring self-esteem by living up to the standard of this worldview. However, Teresi recounted Solomon saying that cultural buffers did not necessarily work for everyone, identifying associated maladaptive practices in dealing with death that were due to a lack of effective cultural symbols.

Rachel Menzies, a clinical psychologist, through her interesting work in associating salience mortality with an array of mental health issues (Menzies 2018; also see Menzies and Dar-Nimrod 2017; Menzies et al. 2015), asserts that a fear of death can generate a feeling of "powerlessness, loneliness, and meaninglessness" and for some individuals may seriously weaken their "experience of happiness or peace" (Menzies 2018, p. 1). 
One of the most glaring reasons for the fear and avoidance of death, according to Philipp Aries, is its obscure nature and the rupture that it brings into an individual's life (Aries 1974). Others have related that the fear and avoidance of death in a secular world results from death being stripped of its religious significance that renders specific values and meanings. For instance, Shai Lavi, in his study of euthanasia in the United States in The Modern Art of Dying, argues that with the technical search for mastery over death, the mode of dying has shifted from a "work of art to a product of technique" (Lavi 2005, p. 4). According to Lavi, since the end of the nineteenth century, death and dying in the West have been defined in relation to medicine, not religion. For Haider Warraich, modern death has become "secular, sterile, and singular" (Warraich 2017, p. 8). In understanding death, Warraich emphasizes the importance of knowing how we are responding to death:

Perhaps the most primitive aspect of death is how we respond to it, how we spend most of our lives imagining it away, how we fear it as some sort of unnatural schism in space-time. Every time we talk about death, the food seems terrible, the weather seems dour, the mood sullen. Every time we think about death, we get so depressed we can't hold a meaningful thought in our heads. Many families talk about death only after their loved one is in the ICU, hooked up to more gadgets than Iron Man. (Warraich 2017, p. 8)

\subsection{Death: Collective Cultural Reference}

In contrast, Tibetan Buddhist culture seems to have taken a different approach to being reminded of mortality, arguably a much more adaptive coping mechanism. Tibetans see death as a reality of life that is pertinent in every step of walk in our life. Whereas a lay Tibetan would tell me that death serves as a potent reminder to lead a morally ethical life, Tibetan doctors often shared with me how their philosophical understanding of death aids them in caring for the dying. Buddhist practitioners, in turn, told me how their nuanced psycho-philosophical knowledge of death and dying affords a potential vantage point for investigating the true self. In that light, Tibetans that I interviewed and observed do not make an attempt to conquer or tame death, nor eschew death, but they endeavor to change their relationship with death vis-à-vis their different capacities based on their education and practice of Buddhist philosophy and psychology.

For example, based on the survey study I conducted, 86 percent of monks, 82 percent of Tibetan medical doctors, and 78 percent of lay Tibetans I sampled, although fearful of death, see death as a vital facet of life-reminders of which help to motivate them to lead an ethical life and thus secure a better next life. When I asked a follow-up question of why they fear death, the majority of them responded by saying that they do not feel prepared enough for the next life. Some responders told me they were scared of the pain and suffering that they might experience while dying, and some said they fear what might happen at the time of death. Nonetheless, we can extrapolate these results based on the average responses that their fear of death was more about how they would fare in the next life rather than the death itself. Likewise, most of the responders (91\% monastic and 84\% laypeople) agreed that death is an opportune moment for spiritual development.

I found that, in general, death plays a role as a collective cultural reference for Tibetans. Importantly, the relatability between Tibetan medical doctors and Buddhist monks with regard to their conceptions of death and caring for the dying was critical for my research. These two stakeholders would often complement each other, and at times, when conflict arose while caring for dying people, they would collaborate in negotiating caring for the dying with the surrounding family members.

\subsection{Death as a Psychological Adaptation Cultural Tool}

The intersection between Tibetan medicine and Buddhist psycho-philosophy has served Tibetans well in gaining access to the understanding of the mind and its synergistic relationship to the body (Clifford 1996; Tidwell 2017). The intricate relationship between Tibetan medicine and Buddhist psychology and philosophy is readily apparent when we look at the etiology of 
illness in Tibetan medicine and the root cause of all suffering in Tibetan Buddhism. While Tibetan medicine attributes the root cause of illness to an "ignorant mind that fails to recognize the absence of [an intrinsic] self" (Gonpo 2015, p. 96), Tibetan Buddhism links individuals' default mode of being obsessively focused on a permanent, independent, autopoietic concept of "self" as a cause of suffering (His Holiness the Dalai Lama 1998, p. 18). In essence, both these disciplines see the ignorant mind that misperceives a self as the root cause of all suffering, and hence, the most effective remedy is to engage in contemplative practice in order to investigate the real self or ultimate reality.

David Loy, a scholar of Buddhist and comparative philosophy, develops a fruitful analysis of the relationship between human suffering and self by emphasizing the "void" or the "lack of self" that humans experience. Loy argues that humans engage in different acts to avoid facing the void, but "the dichotomy between being and nonbeing can be conflated by yielding to the side we have been rejecting" (Loy 1992, p. 153). For Loy, absolute "groundlessness" is analogous to complete "groundedness", and thus the real lack has never existed, for no self-existing self has existence separate from the world right from the beginning (ibid., p. 154). He contends that the problem attached to the unsatisfiable lack (of self) is resolved when the realization of nothingness positively leads to a mindset of being free from everything since there is nothing to be attached to. I observed during my fieldwork that in pursuance of self-inquiry, Tibetans employ the Tibetan Buddhist cultural model of death as one of the main psychological adaptation tools.

Varela (1997) recounts Charles Taylor's pertinent remark on humans' relationship to death across cultures during a week-long dialogue in the exploration of the human body and mind between Tibetan Buddhist scholars, including the Dalai Lama, and representatives of Western science and humanism. Taylor, a philosopher known for his seminal work on reimagining identity and morality for a secular age, notes the divergence between Buddhism and other major world religions in dealing with death. Highlighting differences in the concept of an individual identity, Taylor makes a case that the Buddhist approach of familiarizing oneself with the (mis)perception of a self in order to transcend the self has a strong impact on the way death is engaged with among Buddhists, i.e., natural impermanence. On the other hand, in Christianity, Judaism, and Islam, the goal of transforming one's relationship to God comes into play, and hence, the importance of being intimate with God and supranatural permanence: "Death must not separate us from God" (Varela 1997, p. 133). As discussed earlier, we all deal with death differently, informed by our cultural worldviews, and Tibetans, being culturally invested in examining the function and mechanism of mind in order to comprehend the self, have realized that the nature of the mind at the time of death is the most fertile ground to engage in deep meditation (Dorjee 2007).

\subsection{Death as a Moral Supervisor}

Death for Tibetans in southern India is like an invisible authority of law, and each time they catch themselves engaging in behaviors guided by greed, attachment, or anger, they receive imaginary police citations to retract or to be more cautious the next time. Death was often used as a moral reminder, such as, "Have you forgotten you are going to die?" when someone was either too excited, saddened, or irrational, so much so that it has become a sort of dictum. Interestingly, this tactic has been coopted by a popular sociomoral startup app company called WeCroak (https: / /www.wecroak.com/, accessed on 24 May 2021) in America. Inspired by a Bhutanese Buddhist folk saying: "To be a happy person, one must contemplate death five times daily", the WeCroak app invites their clientele with a provocative bold line on their main page: "Find happiness by contemplating your mortality". The app sends out five invitations daily to their subscribers, comprised of quotes about death by poets, philosophers, and notable thinkers, to pause and think about death. This is a different and novel strategy to deal with one's mortality as compared to what Solomon and Menzies have reported in their Terror Management Theory studies. Instead of being 
terrorized or reacting indifferently toward death, the WeCroak app encourages its members to find happiness in the awareness of mortality.

Unlike contemporary Western culture (Aries 1974; Woods 2007), death in Buddhist culture is respected and incorporated into a societal endeavor to encourage behavior conducive to happiness at both the individual and communal levels. Interestingly, when the notions of viewing death as being part and parcel of our existence and of consciousness as a key player at the time of death are juxtaposed with the Buddhist concept of reincarnation, engagement with death becomes more of a commitment and practice-based endeavor.

\subsection{Death as a Means to Attain a Better Life}

Dawa surprised me with her poise and calmness when she spoke to me about her father who had died five days earlier. "Despite difficult last few weeks", she said, "he died the way he had wanted to die. He did not talk much during the last few days before he died; he was having problems breathing and was in pain, but the day he died, he was awake early in the morning, and asked me to read from the bardo tödrol chenmo, [the Tibetan Book of the Dead]. Other family members joined us. Every now and then, he looked uncomfortable, but overall, he seemed like he was at peace. He laid there, eyes closed, would nod at certain words I was reading; and around noon, or a little later, I think, he left his body".

Dawa's seventy-six-year-old father had lived a relatively healthy life, despite the diabetes. (He developed diabetes in his fifties, and in his final days his heart gave up on him due to congestive heart failure.) She told me her father used to be a hot-headed man until he retired from the army more than fifteen years ago and became a dedicated practitioner. "He became a different person", she added. She said her father became more philosophical about life and spent lots of time in spiritual practice, such as reading Buddhist texts, including the Tibetan Book of the Dead, doing prostrations, and listening to teachings by the Dalai Lama and other teachers. I sat there, on the front porch in the late evening of a southern India summer, battling occasional mosquito attacks, listening to Dawa with awe as she spoke about her late father and how she helped him through the last phase of his life. I wanted to know more about her relationship with her father and what she had learned from her experience.

Dawa was in her early thirties and had moved to North America almost a decade ago. I was curious to know how she was able to maintain her relationship with her late father, and most of all, how she was able to do what she did during the last few hours of her father's life. Until then, I had not met any young lay Tibetan who showed much familiarity with the Tibetan Book of the Dead text. I had personally been introduced to the text only a few years previously largely due to my research and I had never felt the need to read the text to enrich my spiritual life. When I asked Dawa how she was able to assist her father when he was dying, particularly staying calm and reading the Tibetan Book of the Dead, she surprised me by saying she was not calm.

"I was nervous for him but reading a particular chapter from the text about the nature of consciousness and how it would change through the course of dying helped me as much as it might have helped my father".

"How long have you been reading the text, and what made you read it?" I asked.

"I had seen my father reading it and he would tell all of us [siblings] to read it too, but it was only when I had a chance to sit in a teaching of a Tibetan rinpoche who explained the importance and benefit of reading the text, both for this life and the next life, that I started to read it".

"Were you able to learn much about your father's spiritual practice since you live abroad?"

"Yes, I was far away but I would come home every winter to go to Bodh Gaya for pilgrimage. He also had another Buddhist text that he would bring with him all the time. The text is about finding your spiritual teacher, familiarizing yourself with your mind, and engaging in preliminary practices that would help to be focused on the time of death".

"Have you read the text?" 
"Yes, I have. It helps to structure my practice".

Dawa's mother, who had been coming around to make sure the mosquito repellent coil she had fixed under the table was intact, came back this time with a text in her hand, and said, "This is the text Dawa is talking about. It is called Kunzang Lamé Shelung [kun bzang bla ma'i zhal lung]".

Kunzang Lamé Shelung was another important Tibetan Buddhist text I had become aware of while in the field. The text is translated as Words of my Perfect Teacher with a subtitle: A Guide to the Preliminaries for the Heart-essence of the Vast Expanse from the Great Perfection (1994). The text is authored by Patrul Rinpoche, a highly revered Buddhist teacher and scholar of the nineteenth century. Patrul Rinpoche, though technically belonging to the Nyingma School of Buddhism, ${ }^{9}$ was known for his non-sectarian work, as attested by Dilgo Khyentse Rinpoche in his Foreword to the translation of the book, "[This book] sets out the paths of the four main schools of Tibetan Buddhism without any conflict between them" (Rinpoche 1994, p. xxvii).

The popularity of Words of my Perfect Teacher is due to its relatability across the community members owing to the style in which it was written that "could speak as easily to rough nomads and villagers as to lamas and monks" (Rinpoche 1994, p. xxxi). Patrul Rinpoche maintained that the purpose of writing the text was primarily to share oral instructions he received from his teacher, benefitting anyone by examining their mind and setting out on the right path. The text offers a "detailed guide to the methods by which an ordinary person can transform his or her consciousness and set off on the path to Buddhahood, the state of awakening and freedom" (ibid., p. xxxi).

Reflecting on my personal experience, I had no idea that my mother, who had decided to become a Buddhist nun a decade prior to the time she died in the winter of 2016, during my fieldwork, had her own preliminary practices of preparing for her final test at the time of death. Along with other Buddhist ritual artifacts, I saw the aforementioned text when I was clearing her rented apartment after her death. I felt sad that I did not get to talk to her about her practice and learn from her, but it was helpful to go through her religious items and the text and to talk to people who were going through a similar trajectory. At least, it gave me a point of reference to imagine what she was practicing and experiencing.

When I asked Dawa if she remembered any conversation during her father's last moments that had impacted her life or spiritual practice, she told me that her father told her to continue studying Buddhist texts and to be a kind person: "You would die well if you knew you had done enough for your next life". She said, "that spoke to me deeply".

For Tibetan Buddhist practitioners, both monastics and laypeople, leading a moralethical life informed by one's awareness of inevitable death is critical because this determines how one dies and the quality of one's next life. However, some practitioners go deeper into studying the nuanced mechanics of the mind and its impacts at the time of dying. In so doing, they work toward using different states of consciousness to amplify their meditation. As one of the practitioners told me, "Death is an opportune moment for spiritual development".

\subsection{Death as a Means to Unmask Ultimate Reality}

For some Tibetan Buddhist practitioners that I interviewed, the functionality of death goes beyond supervising their daily behavior or making sure that they die peacefully so as to make a smooth transition to the next life. These practitioners would tell me that studying and familiarizing oneself with the process of dying actually renders a most fertile avenue to investigate the real nature of the existence of the self. In that endeavor, it presents both the epistemological and ontological modes of inquiry-the means of knowing the real 'self' and the creation of a 'self' that aids in generating resilience and cultivating compassion.

Tibetans use the term snying stobs, literally meaning heart and power or heart-power, which they articulate as the "power of resilience supported by a compassionate heart". As I discussed the different stages of bardo at length earlier, let me briefly shed light on the specific bardo that these practitioners see as the most potent period to engage in meditation in investigating the self. To reiterate, the luminous bardo (chos nyid bardo) 
involving the after-death experience of the clear-light or ground luminosity is considered to be the ultimate nature of mind as pure awareness. This state also parallels the period classified as clinical death in biomedicine, which is not something that everyone might realize. One needs to have experienced this practice during one's life through simulating the dying process in order to gain familiarity and to be able to remain calm and focused so as to realize the moment of "pristine awareness" when death actually occurs (which I will elaborate upon in another article).

According to Buddhist practitioners, by meditating inside the moment of pristine awareness, whether during simulated or actual dying processes, one can develop a state of mind that transcends the self and connects to the universe. Such a "self" in Tibetan Buddhist culture is considered as the "confident self", and instead of carrying feelings of attachment, hatred, or xenophobia, one experiences love, joy, and compassion. This makes sense, because as Geshe Phuntsok, my field supervisor, would say, "When one only thinks about others and does things for others, there is no need to feel insecure, jealous or be attached to something". Not every practitioner admits to a practice of simulating the dying process owing to its association with the highest tantric yoga practice that is considered sacred. However, some practitioners do admit to it in order to guide and encourage other practitioners. For instance, in recent times, the Dalai Lama has often made remarks about his practice of dying five to six times a day.

Nonetheless, it is evident that in Tibetan culture, the hypothesis about death is contingent on how one conducts one's life and what level of spiritual practice one engages in. This determines the kind of death one can have, if not foreseeing the kind of rebirth one would secure. This hypothesis is well supported every time someone like Dawa's father and many others die in harmony with their death and not in conflict with it.

\section{How Can We Die?}

One question that I asked all my interlocutors during fieldwork, with an option that they could skip the question if they felt uncomfortable, was: "How do you wish to die?" None of them skipped the question; but answers varied from "I want to die peacefully without pain", "I want to die with a feeling that I have done everything I could and without any regret", "I want to die with compassion in my heart", and "I want to die without any fear and a feeling like I'm sleeping in my mother's lap" to "I want to die feeling ready and confident for my next life".

It is interesting that almost none of my interlocutors mentioned anything about a wish to die at home with family members. Perhaps it is assumed among them that they would die at home, or it does not matter when and where they die, particularly for initiated Buddhist practitioners. A monk told me that it is all about our mind at the time of death. A Tibetan medical doctor, whose two-year-old daughter died due to complications related to congenital heart disease, said, "It was not easy to see my daughter subjected to all the tubes and hundreds of needle-punctures on the back of her delicate hand, but one needs to be prepared to die well, no matter when and where".

However, the same question might garner quite a different response among communities in Western culture. Modern culture, where death is best avoided or controlled as if it is unavoidable (Neumann 2016; Nuland 1994), does little to aid individuals in forming any kind of relationship and familiarity with death. Medical school, one of the main pertinent institutions, has done little to repair this culturally maladaptive model-not much has changed since the eighties in terms of how little is taught to medical students about death and dying and how to care for the dying (Gawande 2014; Swanson and Cooper 2005). Philippe Aries shows that people in the West used to accept death and were prepared for their time (Aries 1974, pp. 11-14), but modern death has acquired way too many complexities that leave little room for individuals' preference to forecast ways they want to die (Warraich 2017, pp. 45-46). 


\section{Tibetan Cultural Models of Ways of Dying}

The Tibetan refugee population that I studied showed a radically different approach. They seemed not only to have a collective understanding of the importance of familiarizing themselves with death closely but also to have a specific cultural model of ways of dying depending upon how developed individuals are in their spiritual practices.

For instance, Geshe Phuntsok told me that the way one dies is directly related to one's past and future. Past because the dying person's behavioral action and mental habits while alive will determine the way person dies, and future because the way in which a person dies and the mental state at the moment of death will have a strong impact on the person's rebirth. With regard to different ways in which a person might die, he explained that (1) a beginning practitioner who applies death simply to remind herself of impermanence and thus engage in ethical behavior could potentially die without remorse but still be fearful; (2) an intermediate practitioner who, besides living an ethical life, has studied the nature of her mind and how her mind and body would go through changes at the time of dying and has done all the preliminary practices, could potentially die without any remorse and fear; and (3) an adept practitioner who has led an ethical life governed by love and compassion, mastered her understanding of the nature of mind and changes her mind and body will go through at the time of dying, and has simulated the process of dying to gain a lived experience and knows how to transit through each bardo, could die confidently with love and joy.

\section{Conclusions}

The Tibetan Buddhist worldview with regard to death is strikingly different from contemporary Western culture not only in terms of how death is conceived (Dorjee 2007) but also in the way life and death are determined (Gonpo 2015). It is, however, important to be cognizant of the complexity in deciphering attitudes toward death and dying across and within cultures. The analysis of rich and descriptive ethnographic data and extant Western interdisciplinary scholarship in this paper imply how different epistemologies inform and shape divergent understandings of death and dying.

It might sound counterintuitive to consciously think about death, and even more so, to study and become accustomed to death and the process of dying in great detail and invest time to contemplate on such an understanding. Sigmund Freud makes a provocative analysis of the contradictory relationship between our conception of death and our behavior. To illustrate, he writes: " . . that death was natural, undeniable, and unavoidable. In reality, however, we were accustomed to behaving as if it were otherwise ... It is indeed impossible to imagine our own death; and whenever we attempt to do so we can perceive that we are in fact still present as spectators" (Freud 1957, p. 289). Freud argues that at a subconscious level we cannot relate to our mortality and believe that we are immortal. Nevertheless, for Tibetans, the Buddhist concept of reincarnation provides a cultural buffer to prevent or reconcile this potential gap between an understanding of death and enacting behavior surrounding death.

Contrary to the studies of Solomon and colleagues and Menzies, which affirm that reminders of death bring out negative emotions or exacerbates mental illness, the Tibetan coping mechanisms of dealing with death positively and using it as a sociomoral reference point promise benefit at both an individual and societal level. Likewise, if we take into consideration the correlation between the conception of death and care of the dying (Gawande 2014; Swanson and Cooper 2005), the contemporary biomedical attitude that views death as a failure and tries to conquer death via technology and law could profit from borrowing a conceptual framework from the Tibetan tradition of treating death as part of life.

In the same vein, articulating death under the holistic purview of biological, sociocultural, psychological, and spiritual mores could only make it easier and beneficial for all stakeholders-physicians, patients, and family members-in the sphere of end-of-life care. The intimate intersection between Tibetan medicine and Buddhist psycho-philosophical 
elements in caring for terminal patients necessitates a biopsychosociospiritual approach. Moreover, the Tibetan Buddhist practice of mimicking the dying process while alive and choosing to stay in thugs dam meditation during the moments and the transition thereafter produces effects similar to the results of psychedelic studies reported by Pollan and researchers at NYU and Johns Hopkins and Stolaroff-a sense of interconnectedness, profound joy and love, and importantly, a whole new concept of self and one's relationship to others.

Funding: This research was funded by Wenner-Gren Foundation Dissertation Fieldwork Grant and Fulbright-Hays Doctoral Dissertation Research Abroad Grant. The author's time was supported by the National Institute of Health's National Center for Advancing Translational Sciences, grants TL1R002493 and UL1TR002494. The content is solely the responsibility of the author and does not necessarily represent the official views of the National Institutes of Health's National Center for Advancing Translational Science.

Institutional Review Board Statement: This research followed standard criteria on research ethics and data management, as issued by Emory University. Approval for this research was granted by the Institutional Review Board of Emory University, date of approval: 29 July 2015, IRB Review \# IRB00082357.

Informed Consent Statement: This research was explained in detail to all the research participants, and an oral informed consent was obtained from all the people involved in the study.

Data Availability Statement: The data used in this article were collected and analyzed in the framework of an ethnographic research project. Therefore, it will not be shared because of ethical and privacy reasons.

Conflicts of Interest: The author declares no conflict of interest.

\section{Notes}

1 Margaret Lock makes a similar case in her cross-cultural analysis of death (see, for instance, Lock 2002).

2 Geshe (Tib. dge bshes) or Geshema is a Tibetan Buddhist academic degree for monks and nuns. Geshe Lharam, which is the highest degree in Geluk tradition, is considered equivalent to a Ph.D. degree in the Western educational system.

3 Thugs dam is a state of meditation adept Buddhist practitioners engage in after clinical death. While in thugs dam, these practitioners are able to "impede physical flaccidity ordinarily preceding rigor mortis, retain a meditative state, suspend the process of decomposition, maintain warmth in the body" and occasionally, produce a uniquely pleasant fragrance (Zivkovic 2010, p. 176).

4 The persons' names are replaced by pseudonyms in order to ensure anonymity.

5 Men-Tsee-Khang (Tib. House of Medicine and Astro. Science) is a research and education center of Tibetan Medicine in India. The Institute is a premier Tibetan Medical School outside Tibet, re-established by the Dalai Lama in Dharamsala, India, in 1961.

6 Tibetan doctors use pulse reading as one of the primary modes of making a diagnosis (other diagnosis techniques are urine analysis, observing, examining and touching different parts of the body, and talking to patients). Tibetan doctors read patients' radial artery of both hands using each of their six fingers (pointer, middle, and ring) as the medium to decipher functions of internal organs and other related illnesses. I elucidate further on the Tibetan medicine mode of diagnosis in Chapter 4. (Also see Tidwell's ethnographic work on how Tibetan doctors address and treat cancer via pulse and urine analysis, Tidwell 2017, pp. 376-410; Gonpo 1984).

7 For work elaborating on the topic of human consciousness in Tibetan Buddhist psychology, see (Thompson 2015).

8 See Ozawa-de Ozawa-de Silva (2006) in her work on the influence of Buddhism on the Japanese worldview.

9 The Nyingma school is the oldest lineage tradition of the four major schools of Tibetan Buddhism. The other three lineage traditions are Kagyu, Sakya, and Gelug. Nyingma literally means ancient, for it is founded on the first translations of Buddhist scriptures from Sanskrit to Tibetan in the eighth century.

\section{References}

Abramovitch, Henry. 2001. Death and Dying, Sociology of. International Encyclopedia of the Social \& Behavioral Sciences, 3267-70. [CrossRef] Aries, Phillip. 1974. Western Attitudes toward DEATH: From the Middle Ages to the Present. Translated by Patricia Ranum. Baltimore: The Johns Hopkins University Press.

Baron, Leonard, Samd Shemie, Jeannie Teitelbau, and Christopher J. Doig. 2006. Brief Review: History, concept, and controversies in the neurological determination of death. Canadian Journal of Anesthesia 53: 602-8. [CrossRef] [PubMed]

Becker, Ernest. 1973. The Denial of Death. New York: Free Press. 
Beecher, Henry K. 1968. A definition of irreversible coma: Report of the Ad Hoc Committee of the Harvard Medical School to Examine the Definition of Brain Death. JAMA 205: 337-40. [CrossRef]

Beecher, Henry K. 1970. Definition of 'life' and 'death' for medical science and practice. Annals of the New York Academy of Sciences 169: 471-74. [CrossRef] [PubMed]

Belkin, Gary S. 2014. Death before Dying: History, Medicine, and Brain Death. New York: Oxford University Press.

Bishop, Jeffrey P. 2011. The Anticipatory Corpse: Medicine, Power, and the Care of the Dying. Notre Dame: University of Norte Dame Press.

Bloch, Maurice, and Jonathan Parry. 1982. Introduction: Death and the regeneration of life. In Death and the Regeneration of Life. Edited by Maurice Bloch and Jonathan Parry. Cambridge: Cambridge University Press, pp. 1-44.

Braswell, Harold. 2014. Death and Resurrection in US Hospice Care: Disability and Bioethics at the End-of-Life. Ph.D. thesis, ILA Department, Emory University, Atlanta, GA, USA.

Brussel, Leen Van, and Nico Carpentier. 2014. Introduction: Death as a Social Construction. In The Social Construction of Death: Interdisciplinary Perspectives. Edited by Leen Van Brussel and Nico Carpentier. London: Palgrave MacMillan UK, pp. 1-44.

Clifford, Terry. 1996. Tibetan Buddhist Medicine and Psychiatry: The Diamond Healing. New Delhi: Motilal Banarsidass Publishing.

Crowley, Mike, and Shulgin Ann. 2019. Secret Drugs of Buddhism: Psychedelic Sacraments and the Origins of the Vajrayana. Santa Fe: Synergetic Press, ISBN1 9780907791744 (paperback). ISBN2 9780907791751 (ebook).

Dorjee, Gyurdmey. 2007. The Tibetan Book of the Dead: First Complete Translation. Edited by Graham Coleman and Thupten Jinpa. Translated by Gyurdmey Dorjee. New York: Penguin Publishing House.

Freud, Sigmund. 1957. The Standard Edition of the Complete Psychological Works of Sigmund Freud, the Vol. 14. London: Hogarth Press.

Gawande, Atul. 2014. Being Mortal: Medicine and What Matters in the End. New York: Metropolitan Books.

Germano, David. 1997. Dying, death and other opportunities. In Religions of Tibet in Practice. Edited by Donald Lopez. Princeton: Princeton University Press, pp. 493-548.

Gonpo, Y. Yuthok. 1984. rGyud-bZhi (Four Tantra). Dharamsala: Men-Tsee-Khang.

Gonpo, Yuthok Y. 2015. The Basic Tantra and the Explanatory Tantra from the Secret Quintessential Instructions on the Eight Branches of the Ambrosia. Translated by Thokmey Paljor, Pasang Wangdu, and Sonam Dolma. Dharamsala: Men-Tsee-Khang Publications.

Green, James W. 2008. Beyond Good Death: The Anthropology of Modern Dying. Philadelphia: University of Pennsylvania Press.

Greenberg, Jeff, Sheldon Solomon, and Tom Pyszczynski. 1997. Terror management theory of self-esteem and cultural worldviews: Empirical assessments and conceptual refinements. In Advances in Experimental Social Psychology. Edited by Mark P. Zanna. San Diego: Academic Press, vol. 29, pp. 61-139.

Griffiths, Roland R., Matthew W. Johnson, Michael A. Carducci, Annie Umbricht, William A. Richards, Brian D. Richards, Mary P. Cosimano, and Margaret A. Klinedinst. 2016. Psilocybin produces substantial and sustained decreases in depression and anxiety in patients with life-threatening cancer: A randomized double-blind trial. Journal of Psychopharmacology 30: 1181-97. [CrossRef] [PubMed]

Grob, Charles S., Anthony P. Bossis, and Roland R. Griffiths. 2013. Use of the Classic Psilocybin For Treatment of Existential Distress Associated with Cancer. In Psychological Aspects of Cancer. Edited by Brian Carr and Jennifer Steel. Boston: Springer, pp. 291-308.

Gross, D. Gregory. 2003. Deconstructing death: Toward a poetic remystification and all that jazz. Journal of Poetry Therapy 16: 71-82. [CrossRef]

Hajicek-Dobberstein, S. 1995. Soma siddhas and alchemical enlightenment: Psychedelic mushrooms in Buddhist tradition. Journal of Ethnopharmacology 48: 99-118. [CrossRef]

Halifax, Joan. 2008. Being with Dying: Cultivating Compassion and Fearlessness in the Presence of Death. Boston: Shambhala Publications. Hertz, Robert. 1960. Death and the Right Hand. London: Cohen \& West.

His Holiness the Dalai Lama. 1998. The Four Noble Truths: Fundamentals of the Buddhist Teachings. Edited by Dominique Side. Translated by Thupten Jinpa. London: Thorsons.

Jacobsen, Michael Hviid. 2013. Deconstructing Death-Changing Cultures of Death, Dying, Bereavement and Care in the Nordic Countries. Odense: University of Southern Denmark Studies in History and socIal Sciences.

Kaufman, Sharon R. 2005. ... And a Time to Die: How Hospitals Shape the End of Life. New York: Scribner.

Kaufman, Sharon, and L. Morgan. 2005. The Anthropology of the Beginnings and Ends of Life. Annual Review of Anthropology 34: 317-41.

Korein, Julius. 1978. The Problem of Brain Death. Annals of the New York Academy of Sciences 315: 19-38. [CrossRef] [PubMed]

Kubler-Ross, Elizabeth. 1969. On Death and Dying: What the Dying have to Teach Doctors, Nurses, Clergy, and Their Own Family Members. New York: Scribner Classics.

Lamb, David. 1985. Death, Brain Death, and Ethics. Albany: SUNY Press.

Laureys, Steven. 2005. Death, unconsciousness and the brain. Nature Reviews Neuroscience 6: 899-909. [CrossRef] [PubMed]

Lavi, Joshua Shai. 2005. The Modern Art of Dying: A History of Euthanasia in the United States. Princeton and Oxford: Princeton University Press.

Lock, Margaet. 2002. Twice Dead: Organ Transplants and the Reinvention of Death. Berkeley: University of California Press.

Loy, David. 1992. Avoiding the Void: The Lack of Self in Psychotherapy and Buddhism. The Journal of Transpersonal Psychology 24: 151-79.

Magnus, David. 2015. Persistent Problems in Death and Dying. The American Journal of Bioethics 15: 1-2. [CrossRef] [PubMed]

Menzies, Rachel E. 2018. Death Anxiety: The Worm at the Core of Mental Health. Psych 2018: 40. 
Menzies, Rachel E., and Ilan Dar-Nimrod. 2017. Death anxiety and its relationship with obsessive compulsive disorder. Journal of Abnormal Psychology 126: 367-77. [CrossRef] [PubMed]

Menzies, Ross G., Rachel E. Menzies, and Lisa Iverach. 2015. The role of death fears in Obsessive Compulsive Disorder. Australian Clinical Psychology 1: 6-11.

Metcalf, Peter, and Richard Huntington. 1979. Celebrations of Death: The Anthropology of Mortuary Ritual. London, New York and Melbourne: Cambridge University Press.

Mollaret, Pierre, and M. Goulon. 1959. The depassed coma (preliminary memoir). Revue Neurologique 101: 3-15. (In French). [PubMed]

Neumann, Ann. 2016. The Good Death: An Exploration of Dying in America. Boston: Beacon Press.

Norwood, Frances. 2009. The Maintenance of Life: Preventing Social Death Through Euthanasia Talk and End-of-Life Care-Lessons from the Netherlands. Durham: Carolina Academic Press.

Nuland, B. Sherwin. 1994. How we Die: Reflections on Life's Final Chapter. New York: A.A. Knopf.

Ozawa-de Silva, Chikako. 2006. Psychotherapy and Religion in Japan: The Japanese Introspection Practice of Naikan. New York: Routledge.

Palgi, Phyllis, and Henry Abramovitch. 1984. Death: A Cross-Cultural Perspective. Annual review of Anthropology 13: 385-417. [CrossRef]

Pollan, Michael. 2018. How to Change Your Mind: What the New Science of Psychedelics Teaches Us About Consciousness, Dying, Addiction, Depression, and Transcendence. New York: Penguin Press.

Riley, John W., Jr. 1983. Dying and the Meanings of Death: Sociological Inquiries. Annual Review of Sociology 9: 191-216. [CrossRef]

Rinpoche, Patrul. 1994. Words of My Perfect Teacher: A Complete Translation of Classic Introduction to Tibetan Buddhism, Revised Edition. Padmakara Translation Group with a Foreword for the Dalai Lama. London: Altamire Press.

Robben, CGM Antonius. 2004. Death and Anthropology: An Introduction. In Death, Mourning, and Burial: A Cross-Cultural Reader. Edited by Antonius Cornelis Gerardus Maria Robben. Hoboken: Blackwell Publishing, pp. 1-16.

Seneca. 2018. How to Die: An Ancient Guide to the End of Life. Translated by James S. Romm. Princeton and Oxford: Princeton University Press.

Solomon, Sheldon, Jeff Greenberg, and Tom Pyszczynski. 1991. A Terror Management Theory of Social Behavior: The Psychological Functions of Self-Esteem and Cultural Worldviews. In Advances in Experimental Social Psychology. New York: Academic Press, vol. 24, pp. 93-159.

Stolaroff, Myron. J. 1999. Are Psychedelics Useful in the Practice of Buddhism? Journal of Humanistic Psychology 39: 60-80. [CrossRef]

Swanson, Jan, and Alan Cooper. 2005. Front Matter. In Physician's Guide to Coping with Death and Dying. Montréal: McGill-Queen's University Press, Available online: http:/ / www.jstor.org/stable/j.ctt805z9.1 (accessed on 8 July 2021).

Tart, Charles T. 1991. Influences of previous psychedelic drug experiences on students of Tibetan Buddhism: A preliminary exploration. The Journal of Transpersonal Psychology 23: 139-73.

Teresi, Dick. 2012. The Undead: Organ Harvesting, the Ice Water Test, Beating-Heart Cadavers-How Medicine Is Blurring the Line between Life and Death. Rome: Pantheon.

Thompson, Evan. 2015. Waking, Dreaming, Being: Self and Consciousness in Neuroscience, Meditation, and Philosophy. New York: Columbia University Press.

Tidwell, Tidwell L. 2017. Imbibing the Text, Transforming the Body, Perceiving the Patient: Cultivating Embodied Knowledge for Tibetan Medical Diagnosis. Ph.D. thesis, Anthropology Department, Emory University, Atlanta, GA, USA.

Varela, Francisco J., ed. 1997. Sleeping, Dreaming, and Dying: An Exploration of Consciousness with the Dalai Lama. Boston: Wisdom Publications. Warraich, Haider. 2017. Modern Death: How Medicine Changed the End of Life. New York: St. Martin's Press.

Woods, Timothy J. 2007. Death in Contemporary Western Culture. Islam and Christian-Muslim Relations 18: 333-43. [CrossRef]

Zivkovic, Tanya. 2010. The Biographical Process of a Tibetan Lama. Ethnos 75: 171-89. [CrossRef]

Zivkovic, Tanya. 2014. Death and Reincarnation in Tibetan Buddhism: In-between Bodies. London and New York: Routledge. 